\title{
Electrochemical activation of graphene at low temperature: the synthesis of three-dimensional nanoarchitectures for high performance supercapacitor and capacitive deionization
}

\author{
M. Sh. Zoromba ${ }^{1,2}$, M. H. Abdel-Aziz, ${ }^{1,3}$, M. Bassyouni ${ }^{1,4}$, Saud Abdulaziz Gutub ${ }^{5}$, \\ Denisa Demko ${ }^{6}$, Amr M. Abdelkader \\ ${ }^{1}$ Chemical and Materials Engineering Department, King Abdulaziz University, Rabigh \\ 21911, Saudi Arabia \\ ${ }^{2}$ Department of Chemistry, Faculty of Science, Port Said University, Port Said, Egypt. \\ ${ }^{3}$ Chemical Engineering Department, Faculty of Engineering, Alexandria University, \\ Alexandria, Egypt \\ ${ }^{4}$ Department of Chemical Engineering, Higher Technological Institute, Tenth of \\ Ramadan City, Egypt \\ ${ }^{5}$ Civil Engineering Department, King Abdulaziz University, Rabigh 21911, Saudi \\ Arabia \\ ${ }^{6}$ Department of Engineering, University of Cambridge, Cambridge, CB3 OFA, UK \\ ${ }^{7}$ National Graphene Institute (NGI), University of Manchester, Booth Street East, \\ Manchester, M13 9QS, UK \\ *Corresponding author. Tel.: +441223 748349, Fax: +44 - 1223 - 748348, *E-mail \\ address: aa494@cam.ac.uk
}

\begin{abstract}
An electrochemical technique is developed to activate graphene oxide (GO) at relatively low temperature and assemble it into porous electrodes. The activation process is carried out in molten $\mathrm{KOH}$ by switching the polarity between 2 symmetrical GO electrodes. The electrochemically activated graphene (ECAG) showed specific surface area as high as $2170 \mathrm{~m}^{2} \mathrm{~g}^{-1}$ and nanometer-sized pore created at a temperature as low as $450{ }^{\circ} \mathrm{C}$. The ECAG electrode shows a significant enhancement in the electrochemical activity and thus improved electrochemical performance when being used as electrodes in supercapacitors and capacitive deionization (CDI) cells. A specific capacitance of $275 \mathrm{~F} \mathrm{~g}^{-1}$ is obtained in $6 \mathrm{M} \mathrm{KOH}$ electrolyte, and $189 \mathrm{~F} \mathrm{~g}^{-1}$ in $1 \mathrm{M} \mathrm{NaCl}$ electrolyte, which maintains $95 \%$ after 5000 cycles. The desalination capacity of the electrodes was evaluated by a batch mode electrosorption experiment. The ECAG electrode was able to remove $14.25 \mathrm{mg}$ of salts per gram of the active materials and satisfy high adsorption rate of $2.01 \mathrm{mg} \mathrm{g}^{-1}$ $\mathrm{min}^{-1}$. The low energy consumption of the CDI system is demonstrated by its high charge efficiency, which is estimated to be 0.83 .
\end{abstract}

Keywords: molten salts, desalination, porous electrodes, sponge-templated, electrosorption, ultracapacitor 


\section{Introduction:}

Capacitive deionization (CDI) is an emerging water desalination technology that represents a more energy-efficient alternative to reverse osmosis, electrodialysis, and distillation.1-2 The process is based on passing the salty water between two porous electrodes, and when electric potential is applied, electrochemical double layer formed at the surface and ions are electrostatically attracted to the electrodes, resulting in purifying the water. ${ }^{3-4}$ The adsorbed ions can then easily be removed from the electrodes by reversing the polarity or shortcircuiting the cell. ${ }^{1,4}$ As so, CDI crudely shares the same operating principle of the electrochemical double layer (ECDL) supercapacitors. In fact, CDI systems have the ability to store energy within the double layer charge, exactly as in ECDL supercapacitors.

For these kinds of ECDL devices, the electrode material and structure play significant roles in the device performance. ${ }^{3,5}$ Indeed, engineering the electrodes to maximise the specific surface area increases the electrolyte/electrode interface and consequently enhances the efficiency of the device. Traditionally, both CDI and ECDL supercapacitors used porous carbon to engineer both positive and negative electrodes. $^{6-8}$ However, with the emerging of graphene at the beginning of this millennium, many attempts have considered using graphene as electrodes material. ${ }^{9-10}$ Theoretically, graphene with its unique structure as one atomic thin layer of carbon possesses the highest known specific surface area $\left(2600 \mathrm{~m}^{2} \mathrm{~g}^{-1}\right)$, which makes it ideal for ECDL devices. ${ }^{11-13}$ Practically, most of the attempts reported so far could not engineer graphene-electrode that can benefit from the high theoretical specific surface area, mainly because of the aggregation of the graphene flakes during the preparation of the electrode. ${ }^{14-15}$ Several strategies have been examined to minimise the aggregation of the graphene sheets. Mixing graphene with carbon nanotubes, conductive polymers, metal or metal oxides/hydroxide nanoparticles prevented re-stacking of the graphene sheet. ${ }^{16-18}$ However, the electrochemical stability of the supercapacitors becomes poor due to the inherent instability of the functionality under the electrochemical conditions. Using threedimensional, wrinkled or corrugated undoped graphene is a promising solution to prevent aggregation and maintain good cyclic stability. ${ }^{19-23}$ Chemical activation of 
graphene has also been investigated to create pores in the graphene flakes and improve the electrochemical performances of graphene electrodes in supercapacitors. ${ }^{24-27}$

Herein, we fabricate high surface area hierarchical structure graphene electrode for the purpose of using it in ECDL supercapacitors and CDI system for water desalination. The present work deposited graphene oxide (GO) on 3D metal foam substrate as a template followed by an electrochemical reduction and activation in molten $\mathrm{KOH}$ at $450{ }^{\circ} \mathrm{C}$. The reduction process was able to efficiently remove the oxide functional groups from the starting GO raw material and creates some micro and nanopores in the graphene flakes. Also, quenching from the high temperature of the molten salt results in producing curly morphology that prevents restacking.

\section{Experimental section}

\section{Materials and Electrodes Peroration}

All the chemicals were purchased from Sigma-Aldrich and used without further purification, except graphite, which was supplied by Graphexel (grade 2369). GO was prepared by a modified Hummers method as described elsewhere. ${ }^{28-29}$

$\mathrm{GO}$ was deposited electrophoretically on $\mathrm{Ni}$ foam from a $4 \mathrm{mg} \mathrm{ml}^{-1}$ solution. Typically, a constant current of $10 \mathrm{~mA}$ was applied for 60 seconds between $\mathrm{Ni}$ foam anode and $\mathrm{Cu}$ cathode. The Ni foam coated with graphene was then dried under vacuum for 1 hour and at $60{ }^{\circ} \mathrm{C}$. The coating and drying steps were repeated for three times until the Ni foam was fully covered with graphene.

The reduction and activation processes were conducted in a molten salt reactor consisting of a vertical tubular Inconel ${ }^{\circledR}$ vessel with $70 \mathrm{~mm}$ inside diameter, and 600 $\mathrm{mm}$ height placed inside a Vecstar ${ }^{\circledR}$ ceramic-lined $100 \mathrm{~mm}$ vertical tube furnace (Figure S5 in the supporting information). Further details about the molten salt electrochemical setup can be obtained elsewhere. ${ }^{30-31}$ The GO-coated Ni foam was served as both the cathode and anode in a two-terminal cell in which molten $\mathrm{KOH}$ was the electrolyte. The GO-coated $\mathrm{Ni}$ foams were connected to a stainless rod, which served as the current collectors and attached to the outer cell via holes drilled in the reactor lid. About $200 \mathrm{~g} \mathrm{KOH}$ was charged into a zirconium crucible and placed 
at the bottom of the Inconel ${ }^{\circledR}$ vessel. The furnace was then heated to $150{ }^{\circ} \mathrm{C}$ at a rate of $1{ }^{\circ} \mathrm{C} \mathrm{min}^{-1}$ under a contentious flow of Ar and held at that temperature for 12 hours. The temperature was then ramped to $450{ }^{\circ} \mathrm{C}$ and held at that temperature for 30 minutes before applying the potential. A potential difference of 2.5 and $-2.5 \mathrm{~V}$ was swiped between the two electrodes every 60 seconds using Iviumstat Electrochemical Interface. The total run for the electrolysis process was 60 minutes. The electrodes were then removed from the salts and allowed to cool under argon. After removed from the furnace, the electrodes were washed with distilled water and ethanol and dried under vacuum for 3 hours.

The graphene coated $\mathrm{Ni}$ was then pressed at $1 \mathrm{MPa}$ to obtain the final electrodes, without adding binder or conductive additives. The mass of the active materials was approximately $0.6 \mathrm{mg}$.

\section{Supercapacitor electrochemical performance}

The electrochemical performance of the supercapacitor devices was tested in a conventional three-electrode and two electrodes coin cells. Two types of electrolytes were used; $1 \mathrm{M} \mathrm{NaCl}$, and $6 \mathrm{M} \mathrm{KOH}$. The later was used to obtain quantitative values that can be compared with other published supercapacitor devices. The electrochemical performance of the samples was measured by cyclic voltammetry and galvanostatic spectroscopy using an Iviumstat Electrochemical Interface. The specific capacitance was calculated from the CV curve using the following equation, $\mathrm{Cs}\left(\mathrm{F} \mathrm{g}^{-1}\right)=\mathrm{I} \Delta \mathrm{t} / \Delta \mathrm{Em}$, where $\mathrm{I}$ is the current loaded $(\mathrm{A}), \Delta \mathrm{t}$ is the discharge time (s), $\Delta \mathrm{E}$ is the potential change during the discharge process, and $m$ is the mass of active material (g).

\section{Batch mode CDI experiments}

The CDI performance of the electrodes was measured in a batch mode electrosorption experiment, in a continuously flowing system. In each experiment, the aqueous solution was cycled in the cell with a peristaltic pump. A flow rate around $10 \mathrm{ml} \mathrm{min}$-1 was applied, and a total solution volume of $15 \mathrm{ml}$ was maintained. The typical electrosorption experiment was conducted in a $\mathrm{NaCl}$ solution with an initial conductivity around $160 \mu \mathrm{sm}^{-1}$ ( 87ppm NaCl). The concentration change of the solution was measured using ion conductivity meter at the outlet of 
the cell, where the solution was released. The salt concentration was obtained according to a calibration table between the conductivity and the concentration made prior to the experiment. The charging potential was applied until saturation; i.e. until the conductivity of the outlet solution stopped decreasing. The discharging cycle was stopped when the conductivity of the outlet solution reached the initial conductivity.

\section{Materials Characterisation}

Fourier-transform infrared (FTIR) spectroscopy was performed at room temperature using a Varian 3100 FTIR spectrometer. The samples were ground with potassium bromide and then pressed into disks. X-ray photoelectron spectroscopy (XPS) was performed using a Kratos Axis Ultra X-ray photoelectron spectrometer equipped with an aluminium/magnesium dual anode and a monochromated aluminium X-ray source. Thermogravimetric analysis (TGA) was completed using a Jupiter Netzsch STA $449 \mathrm{C}$ instrument heated at $10{ }^{\circ} \mathrm{C} \mathrm{min}^{-1}$ from room temperature to $700{ }^{\circ} \mathrm{C}$ under a nitrogen gas flow. X-ray diffraction (XRD) analysis was conducted using a Philips X'PERT APD powder X-ray diffractometer $(\lambda=1.54 \AA$, CuK $\alpha$ radiation). The N2 adsorption-desorption isotherms of the samples were measured at $77 \mathrm{~K}$ using ASAP 2020 to obtain the specific surface area and pore size distribution. Prior to adsorption/ desorption measurements, all samples were degassed at $200{ }^{\circ} \mathrm{C}$ for $12 \mathrm{~h}$ under vacuum. The specific surface area was calculated from the BrunauerEmmett-Teller (BET) plot of the nitrogen adsorption isotherm and the pore size distribution of the samples was calculated from adsorption branch isotherms by Barrett-Joyner-Halenda (BJH) method. Raman spectra were obtained using a Renishaw 1000 spectrometer coupled to a $633 \mathrm{~nm}$ He-Ne laser. The laser spot size was $\sim 1-2 \mu \mathrm{m}$, and the power was approximately $1 \mathrm{~mW}$ when the laser was focused on the sample using an Olympus $\mathrm{BH}-1$ microscope. Scanning electron microscopy (SEM) was performed using a Philips XL30 FEG SEM, operating at an accelerating voltage of $5 \mathrm{kV}$. 


\section{Results and discussion:}

Reducing and functionalizing GO under high pressure and moderated temperature are well studied by the hydrothermal techniques. To obtained porous structures suitable for ECDL electrodes, the hydrothermal graphene is usually post-treated by, for example, freeze-drying at cryogenic conditions. ${ }^{19}$ The mechanical stability of such materials under a contentious flow of water is always questionable due to the weak bond between the graphene flakes and the internal stress induced by the aggressive quenching treatment. In the current work, we developed single step technique to produce mechanically stable 3D architectures from graphene oxide. Figure 1 illustrates the fabrication of the 3D electrode. Quenching the GO-coated electrodes from $450{ }^{\circ} \mathrm{C}$ to the room temperature resulting in a non-equilibrium cooling and trapped some of the salts to solidified between the flakes. As can be seen from the SEM images in Figure 2, the graphene flakes have a porous crumpled structure that is attached and supported by the $\mathrm{Ni}$ foam as the backbone. The SEM images also show wrinkles on the surface of the flakes, which work as nanochannels providing a short pathway for the electrolyte between the flakes. The mechanical stability of the electrode was first tested by passing a stream of water, and no visible changes were observed in the solution. This stability is important for the capacitive deionization process. 


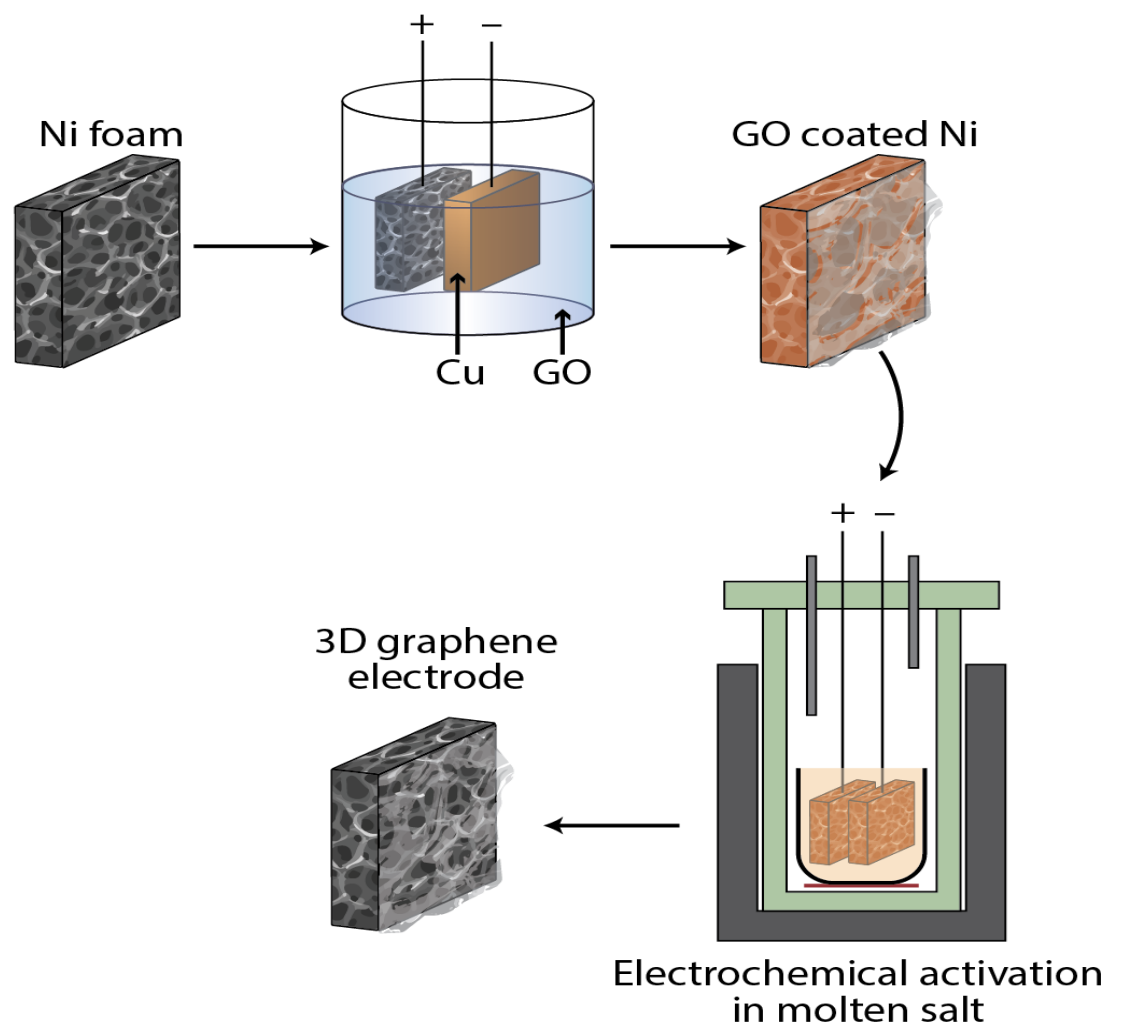

Figure 1: Schematic Illustration of the electrode fabrication and the electrochemical activation process.
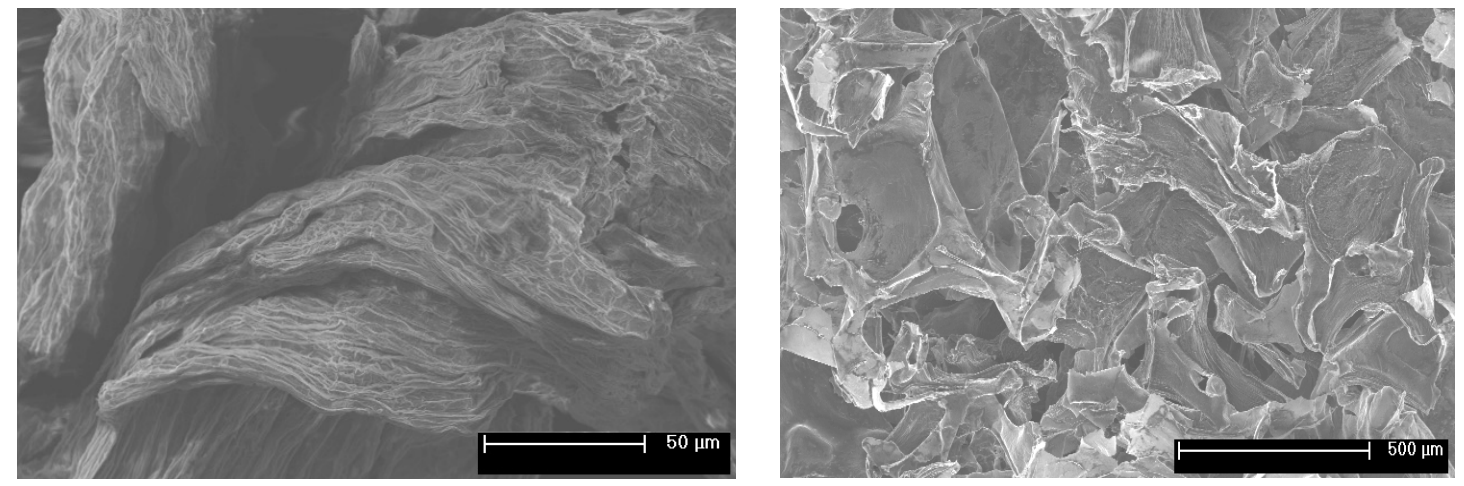

Figure 2: SEM image of the ECAG electrode at various magnifications

The performance of any capacitive device depends on a number of parameters, including specific surface area, chemical composition, and pore structure of the electrode materials. The pore structure and the surface area were evaluated by the $\mathrm{N}_{2}$ adsorption/desorption analysis and the resulted isotherm measured at $70 \mathrm{~K}$ is illustrated in Figure 3a. The isotherm shows typical type IV according to the IUPAC, with a distinct hysteresis loop in the medium to high-pressure regions (P/PO range 0.4 1.0), implying the presence of a large number of mesopores in the ECAG. ${ }^{32}$ The isotherm also shows an abrupt rise at low pressure that corresponds to the 
adsorption at micropores. The pore size distribution (Figure 3b) confirmed the presence of mesopores peaked at $\sim 4.1 \mathrm{~nm}$ and micropores peaked at $1.7 \mathrm{~nm}$. The BET surface area is $2170 \mathrm{~m}^{2} \mathrm{~g}^{-1}$ calculated in the $\mathrm{P} / \mathrm{PO}$ range $0.1-0.3$. This result shows that the electrochemical technique used in the current work can activate graphene and create micropores. The activation mechanism is slightly different than that of the traditional $\mathrm{KOH}$ activation of carbon materials. The conventional $\mathrm{KOH}$ activation is taking place in three steps: (I) etching carbon with a redox reaction as shown by equations 1 to 3 at temperature above $400{ }^{\circ} \mathrm{C}$, (II) the reaction of carbon with the $\mathrm{H}_{2} \mathrm{O}$ or $\mathrm{CO}_{2}$ gases further creates more pores through reaction 4 and 5 , at temperature above $700{ }^{\circ} \mathrm{C}$, and (III) intercalation of metallic $\mathrm{K}$ (produced from equations 1-3) with graphite, resulting in irreversible expansion of the carbon lattice. $^{33}$ It is widely accepted that the $\mathrm{KOH}$ activation is more effective at a temperature above $600{ }^{\circ} \mathrm{C}$. However, in the case of GO activation, the story is different. The GO flakes are heavily populated with defects and oxygen functional groups that may contribute to the activation process and reduce the required temperature. In fact, activation of $\mathrm{GO}$ by annealing with $\mathrm{KOH}$ at temperatures as low as $450{ }^{\circ} \mathrm{C}$ was reported very recently, but it gave a surface area of less than $500 \mathrm{~m}^{2} \mathrm{~g}$ ${ }^{1.34}$ In the current work, the electrochemical deoxygenating of the oxide groups from the cathode may also involve attacking the graphene basal plane to form any carbon-oxygen ions such as $\mathrm{RCOO}^{-}$or $\mathrm{CO}_{3}^{-2}$ (equation 7). On the anode, the carbon atoms react with different kinds of oxide ions adsorbed on the surface of the graphene that leads to the formation of CO gas (equations 9-11). Both ions and CO formation create pores in the surface.

$$
\begin{array}{cc} 
& 6 \mathrm{KOH}+2 \mathrm{C}=2 \mathrm{~K}+3 \mathrm{H}_{2}+2 \mathrm{~K}_{2} \mathrm{CO}_{3} \\
& \mathrm{~K}_{2} \mathrm{CO}_{3}+2 \mathrm{C}=2 \mathrm{~K}+3 \mathrm{CO} \\
& \mathrm{C}+\mathrm{K}_{2} \mathrm{O}=2 \mathrm{~K}+\mathrm{CO} \\
& \mathrm{CO}_{2}+\mathrm{C}=2 \mathrm{CO} \\
& \mathrm{C}+\mathrm{H}_{2} \mathrm{O}=\mathrm{CO}+\mathrm{H}_{2} \\
\text { Cathode: } & \mathrm{C}-\mathrm{OH}+\mathrm{e}^{-}=\mathrm{OH}^{-} \\
\text {Cathode: } & \mathrm{C}-\mathrm{HCOO}+\mathrm{e}^{-}=\mathrm{HCOO}^{-} \\
\text {Cathode: } & \mathrm{C}-\mathrm{O}+2 \mathrm{e}^{-}=\mathrm{O}^{-2} \\
\text { Anode: } & \mathrm{C}+2 \mathrm{OH}-=2 \mathrm{e}^{-}+\mathrm{H}_{2} \mathrm{O}+\mathrm{CO} \\
\text { Anode: } & \mathrm{C}+\mathrm{O}^{-2}=2 \mathrm{e}^{-}+\mathrm{CO} \\
\text { Anode: } & 4 \mathrm{HCOO}^{-}+2 \mathrm{C}=6 \mathrm{CO}+2 \mathrm{H}_{2} \mathrm{O}+4 \mathrm{e}^{-}
\end{array}
$$



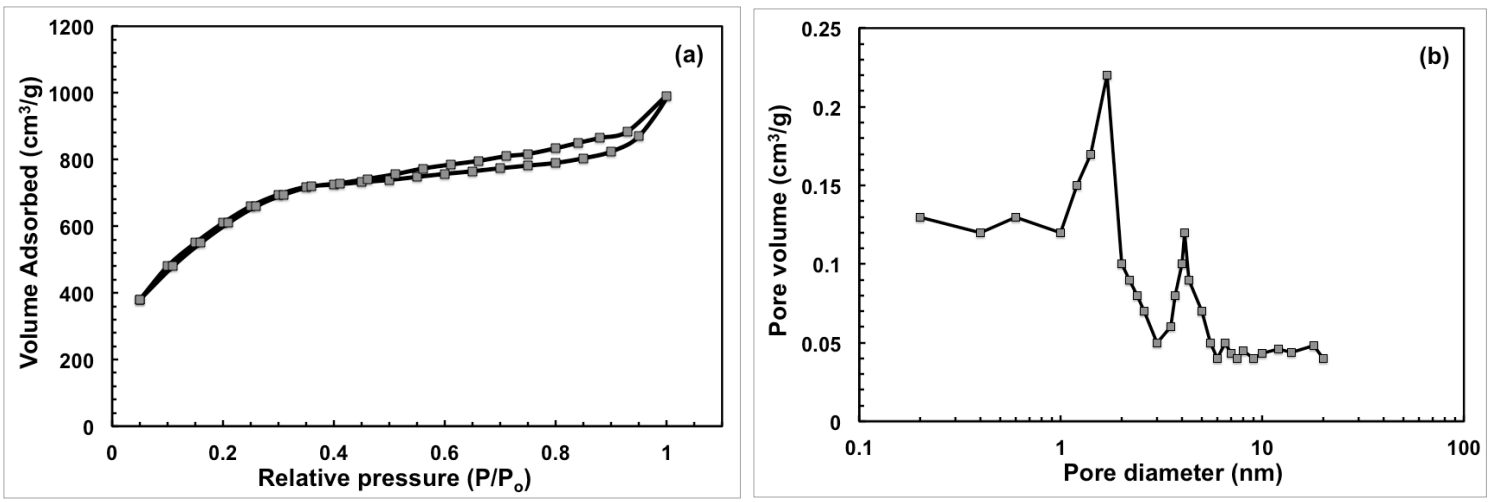

Figure 3: Nitrogen sorption isotherms and BJH pore size distributions for the ECAG.

The chemical composition of $\mathrm{GO}$ after reduction was determined by Fourier transform infrared spectra (FT-IR), and X-ray photoelectron spectroscopy (XPS). FT-IR spectra of the original GO and ECAG are shown in Figure 4c. The GO spectrum shows the typical characteristic peaks of GO: (1) the alkoxy $\mathrm{C}-\mathrm{O}$ stretching vibration at $1053 \mathrm{~cm}^{-1}$, (2) epoxy $\mathrm{C}-\mathrm{O}$ stretching vibration at $1220 \mathrm{~cm}^{-1}$ (3) aromatic $\mathrm{C}=\mathrm{C}$ stretching vibration at $1625 \mathrm{~cm}^{-1}$; (4) $\mathrm{C}=\mathrm{O}$ stretching vibration at $1746 \mathrm{~cm}^{-1}$; and (5) the $\mathrm{O}-\mathrm{H}$ stretching and deformation vibrations at $3420 \mathrm{~cm}^{-1}$ and $1395 \mathrm{~cm}^{-1}$ respectively. ${ }^{35}$ After reduction, the stretching vibration of the oxygen functional groups weakened significantly confirming their efficient removal. The presence of the peak at $1625 \mathrm{~cm}^{-1}$ corresponding to the aromatic $\mathrm{C}=\mathrm{C}$ group after the reduction suggesting that the frame of $\mathrm{sp}^{2}$-bonded carbon atoms was retained well despite the high-temperature nature of the process.

The XPS was also used to identify the chemical composition of the ECAG. The survey spectra (Figure S1 in the supporting information) shows that the intensity ratio of the C1s/O1s peaks of ECAG clearly is much higher than that of GO, implying that a substantial quantity of oxygen functional groups was removed during the electrochemical reduction. The XPS spectra of the C1s peak for the GO (Figure 4a) and ECAG (Figure 4b) also confirmed the efficient removal of the oxygen functional groups. The C1s peaks of the original GO can deconvolute into 4 peaks associated with $\mathrm{C}-\mathrm{C}$ bond and different oxygen functionality; C-O groups (hydroxyl and epoxy, $\sim 286.5 \mathrm{eV}$ ), C=O (carbonyl, $\sim 288.3 \mathrm{eV}$ ) groups, and O-C=O (carboxyl, $\sim 290.3 \mathrm{eV}$ ) groups. ${ }^{12,36}$ The peaks of the oxygen functionality almost disappeared from the spectrum after the electrochemical treatments, except a small hump at the high 
energy level. We believe that the efficient removal of the oxygen groups is a synergy of the electrochemical deoxygenation at the cathodic step (equations 6-8) as well as the mild thermal annealing. ${ }^{13}$
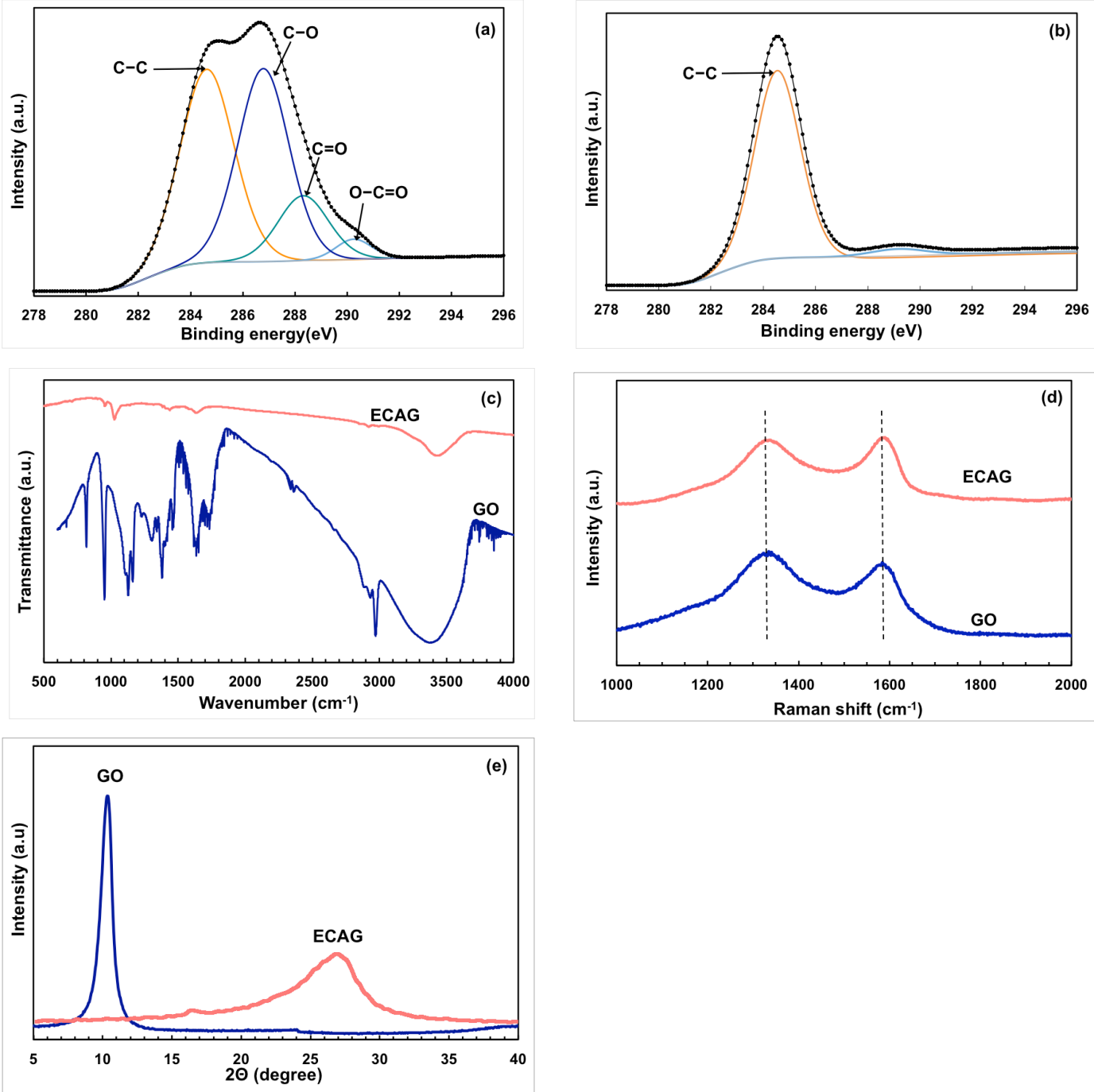

Figure 4: XPS C1 peak comparison of (a) GO, (b) ECAG, (c) FTIR plots for GO and ECAG showing effective removal of the oxygen functional groups, (d) Raman spectra of GO and ECAG showing increase of the $I_{D} / I_{G}$ ratio, (e) XRD spectra of GO and ECAG highlighting the shift of the (002) diffraction peak due to the reduction process.

The change of the structure during the reduction process was investigated using XRD and Raman analysis. The XRD pattern of the GO has a broad peak at $2 \theta=10.3^{\circ}$ reflecting an interlayer distance of $0.8 \mathrm{~nm}$ due to the presence of the oxygen functional groups. After reduction, the peak shifted to $2 \theta=26.3^{\circ}$, the same position of the 002 peak of graphite with an interlayer distance of $0.34 \mathrm{~nm}$ between the graphene layer. ${ }^{37-38}$ The width and the shape of the peak in the XRD pattern of the ECAG can be attributed to the relatively short domain order or turbostratic 
arrangement of stacked sheets. The Raman spectra of GO (figure 4e) shows characteristic $D$ band at $\sim 1345 \mathrm{~cm}^{-1}$ corresponding to breathing mode of $A_{1 \mathrm{~g}}$ symmetry, and $G$ band at $1585 \mathrm{~cm}^{-1}$ corresponding to the $E_{2 g}$ symmetry of $s^{2}$ carbon atoms. After reduction, the $D$ band was shifted to $1335 \mathrm{~cm}^{-1}$ and the $G$ band $1580 \mathrm{~cm}^{-1}$, respectively. The intensity ratio of the $D$ and $G$ bands, $I_{D} / I_{G}$, which conventionally used to describe the defects increases from 0.76 to 1.22 . Such increase in the $I_{D} / I_{G}$ ratio can be attributed to the introduction of the nanopores on the graphene surface as a result of the activation.

The electrochemical performance of the ECAG electrode was investigated in $1 \mathrm{M}$ $\mathrm{NaCl}$ or $6 \mathrm{M} \mathrm{KOH}$ as the electrolyte. The electrochemical properties were evaluated using CV and galvanostatic charge/discharge tests. The CVs recorded at different scan rates are illustrated in Figure $5 \mathrm{a}$ and $5 \mathrm{~b}$. The ideal rectangular (or quasirectangular in the case of $\mathrm{NaCl}$ ) CV curves demonstrate good double layer capacitor behaviour without Faradaic reactions. Even at a fast scan rate of $400 \mathrm{mV} \mathrm{s}^{-1}$, the CV remains rectangular in shape, indicating the high-power capability of the supercapacitor. The weak reduction wave observed between 0.1 to $0.4 \mathrm{~V}$ at medium and high scan rates in $\mathrm{NaCl}$ electrolyte are attributed to the reduction of $\mathrm{Ni}^{3+}$ to $\mathrm{Ni}^{2+}$. The galvanostatic charge/discharge analysis also shows ideal capacitance with the nearly ideal triangular curves. The discharge curves measured in $\mathrm{NaCl}$ electrolyte have slight distortions on the position of $\mathrm{Ni}^{3+}$ reduction potential. However, these bends disappeared at high current densities, and nearly perfect straight lines were recorded, suggesting the contribution of the pseudo-capacitances from the nickel foam is negligible. Furthermore, comparison of the unloaded Ni foam and the ECAG electrode showed clearly that the obtained capacitance is predominantly from the double layer capacitance of ECAG (see supporting information). The absence of any initial drop at the beginning of the discharge cycle suggests very low internal resistance of the cell as a result of the efficient removal of the oxide insulating groups. The calculated gravimetric capacitance in $1 \mathrm{M} \mathrm{NaCl}$ at $0.1 \mathrm{~A} \mathrm{~g}^{-1}$ is $189 \mathrm{~F} \mathrm{~g}^{-1}$. The same value measured in $\mathrm{KOH}$ electrolyte was about $275 \mathrm{~F} \mathrm{~g}^{-1}$. The specific capacitance recorded for the ECAG is one of the highest gravimetric capacitance reported for undoped graphene-based electrodes (see Table S1 in the supporting information). The crumpled curly morphology of the graphene flakes that prevents 
the back stacking and the high surface area mesopores structure provided by the electrochemical activation are responsible for the high capacitance. The supercapacitor device was cycled for 5000 cycles and retained about $95 \%$ of its initial capacitance. This high stability, even at static conditions, is promising for any CDI system.
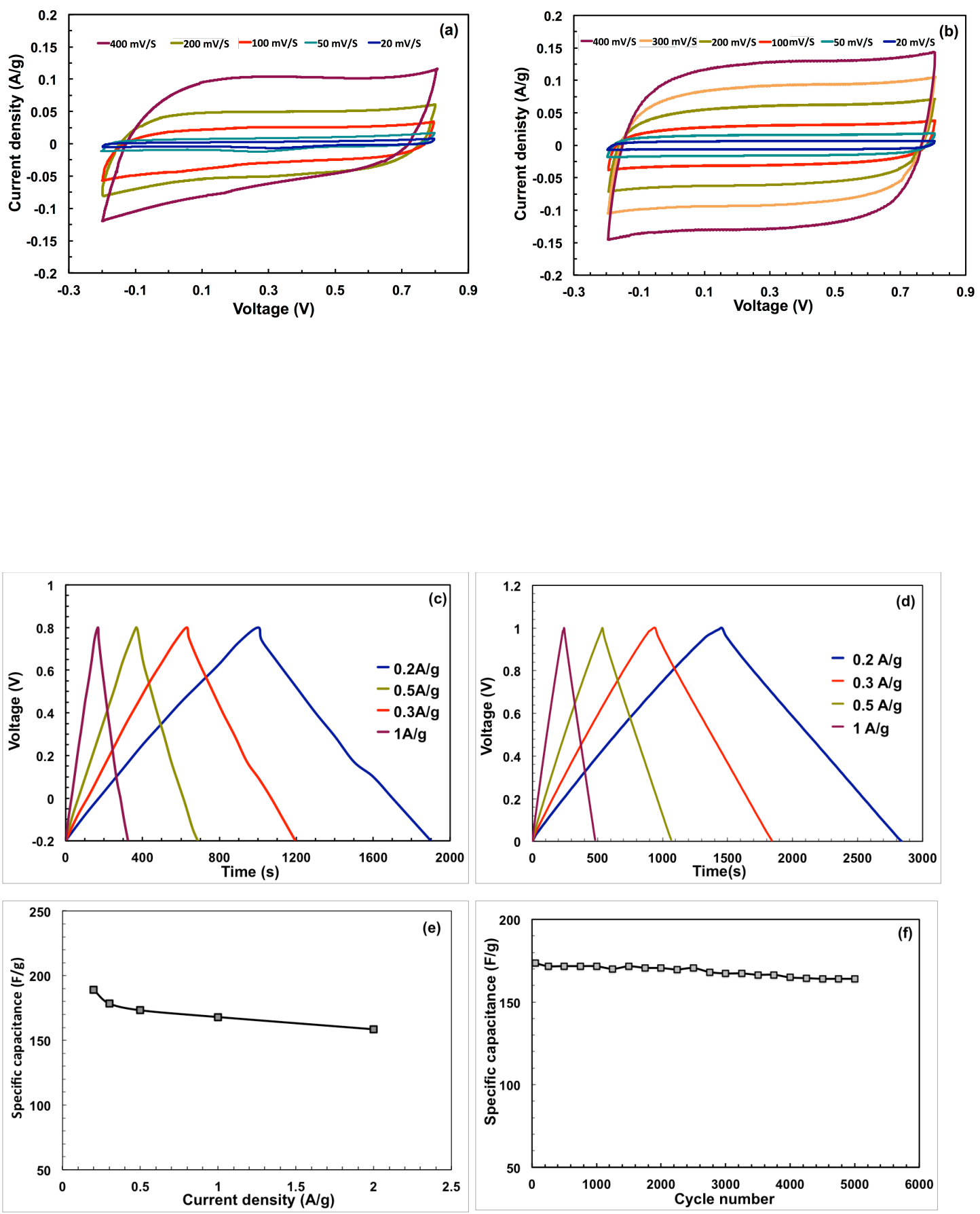
Figure 5: Electrochemical performance of the ECAG electrode; (a) CV in $1 \mathrm{M} \mathrm{NaCl}$, (b) $\mathrm{CV}$ in $6 \mathrm{M} \mathrm{KOH}$, (c) galvanostatic charge/discharge curve in $\mathrm{NaCl}$, (d) galvanostatic charge/discharge in $6 \mathrm{M} \mathrm{KOH},(e)$ change of the specific capacitance with current density in $\mathrm{NaCl}$, and (f) cyclic stability in $1 \mathrm{M} \mathrm{NaCl}$ electrolyte.

For any desalination process, the solution is usually much less concentrated than the electrolyte used for energy storage. This low concentration affects the kinetic of the electrosorption process, and a longer timeframe is required to remove the maximum amount of ions from the salty water. To be able to evaluate the optimum time, we applied different voltages between 2 symmetrical electrodes in a CDI cell and then measured the change in the conductivity of the $\mathrm{NaCl}$ electrolyte (Figure 6a). As a result of the ions moving from the solution to the electrode surface and adsorbed on it, the conductivity of the electrolyte decreased rapidly in the first few minutes. The available surface on the electrode for the ions to be adsorbed gradually reduce until the electrodes become saturated; this is the equilibrium point where the solution conductivity reaches a time-independent value. It is clear that the rate of adsorption in the first stage is faster when a higher voltage is applied. At $1.8 \mathrm{~V}$, the CDI system reached equilibrium after only $450 \mathrm{~S}$. This is eventually much faster than the previously reported materials, which usually needed tens of minutes and sometimes hours to reach their electroabsorption equilibrium under the same conditions (see Table S2 in the supporting information). The average salt adsorption rate, defined as the mass of the salt removed per minute for every gram of the active materials in the electrodes, is calculated to be $2.01 \mathrm{mg} \mathrm{g}^{-1} \mathrm{~min}^{-1}$ (Figure 6b). This is an excellent value compared with other carbon electrodes reported in the literature for CDI. ${ }^{39-40}$
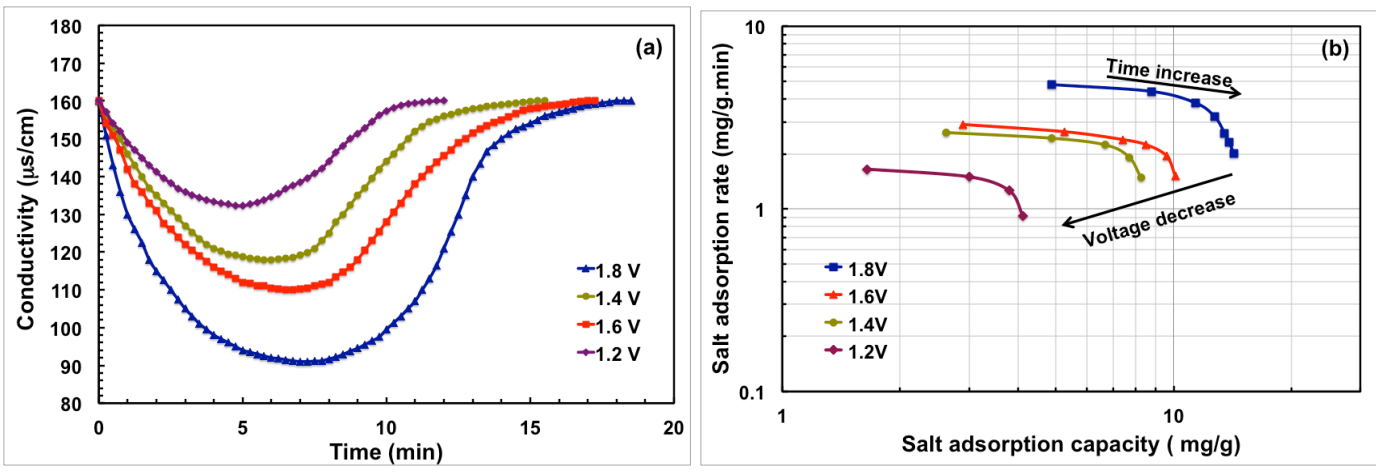

Figure 6: (a) One complete charging/discharging cycle of $\mathrm{NaCl}$ solutions with the ECAG electrodes at different applied voltage, (b) salt removal rate plotted against salt removal capacity measured at different time and different cell potential. 
Beside the electroabsorption rate, the ability of the $C D I$ to remove a maximum amount of the salt per gram of the active materials in the electrodes is also imperative. The maximum electrosorption capacity, calculated from the ratio between the salt adsorption at equilibrium to the weight of the active materials, is about $14.25 \mathrm{mg} \mathrm{g}^{-1}$ at $1.8 \mathrm{~V}$. This value is much higher than that of activated carbon, CNT and rGO-based electrodes at the same conditions, which clearly shows that the high porosity of the activated graphene electrode created more accessible surface for the ions. ${ }^{41-43}$ The electrosorption capacity decreases with the initial concentration of the electrolyte as can be seen in Figure S5d (supporting information). Enhancing the electroabsorption capacity at high concentration can be attributed to two reasons: (1) the electrochemical double layer is more compacted at high salt concentration, resulting in higher electrostatic force and therefore more ions can be adsorbed on the electrode, and (2) the stronger ionic strength accelerate the ion transportation and consequently enhances the electrosorption capacity. ${ }^{44}$

From an energy point of view; energy efficient CDI system should have a high charge capacitance. Charge capacitance, $\Lambda$, is defined as the ratio between the adsorbed salt over charge divided by Faraday's constant. ${ }^{45}$ Therefore, the charge capacitance is an analogue to another metric, current efficient, which is more commonly used in industrial electrochemistry. They both define the ratio between the actual amounts of the ions deposited (adsorbed) on an electrode to the theoretical value that should have been deposited from the invested charge. However, the current efficiency was introduced to describe faradaic processes, and the waste of charge is usually caused by parasitic faradic reactions or electric current leakage for electrolytes with reasonable electronic conductivity. In the case of $\mathrm{CDI}$, there are no faradic reactions before the water decomposition at high potential, and the electronic conductivity of the salty solution is negligible. The reason for the electric charge loss in the traditional $\mathrm{CDI}$ is due to the fact that the adsorption of a counterions (the ions that are opposite in sign to that of the electrical charge of the electrodes) on an electrode is simultaneously associated with the desorption of the coions (the ions that are expelled from the charged surface) from the same electrode. This coion expulsion from the electrodes is the origin for the reduction of $\Lambda$ to values below unity. The calculated charge efficiency for ECAG electrode is 0.83 (Figure S4c in the supporting 
information), which is comparable with other carbon-based electrodes (Table S2 in the supporting information). ${ }^{46}$ Interestingly, the charge efficiency decreased with increasing the applied voltage, as opposed to the expected from CDI cells. ${ }^{46-48}$ However, in recent years there was several studies on the effect of the potential of zero $(\mathrm{PZC})$ charge on the desalination process and they conclude that the charge efficiency of a CDI cell improves when the electrode potentials are placed far beyond their respective PZC. We postulate that the ECAG electrodes have accumulated some surface charges due to the electrochemical nature of the activation and fabrication process. As a consequence of these surface charges, smaller values of the voltage lead to the electrodes potentials being far from their PZC and hence to higher charge efficiencies as previously reported. ${ }^{47,49}$

The excellent performance of the ECAG electrodes in the CDI is related to their 3D hierarchical porous structures. Removing the ions from saline water is taking place in several steps: (i) the diffusion of the salt ions from the bulk solution to the electrode, (ii) the electrosorption of the ions in the electrochemical double layer, and (iii) mass transfer of ions inside the electrode pores. Thus, a good CDI electrode should satisfy both the electroabsorption of the ions in the electrical double layer and the ions transfer processes. The hierarchical structure of the electrode in the present work with its high specific surface area provides more surfaces for the ions adsorption. This large surface area resulted from the 3D arrangement of the graphene on the metal foam templates, the loosely interconnected graphene particles, and the mesopores provided by the activation process. The ions diffusion to and within the electrode is facilitated by the porosity, which provides transport channels and shortens the diffusion pathway. Also, the activation protocol used in the current work provided pores large enough to pass both the counterions and the coions, unlike other activation methods that created pores of less than $1 \mathrm{~nm}$. In fact, the reduction and activation process at high temperatures form more channels between the flakes due to the gas liberation. Some of the residual byproducts, $\mathrm{KOH}$ may get trapped between the flakes, and open more channels when leached out in the washing step. Furthermore, IR drop of the electrode was significantly low, indicating low resistivity due to the effective reduction method and the excellent adhesion between the graphene flakes and the $\mathrm{Ni}$ backbone. The low resistivity of the 
electrode facilitates the electron movements and therefore a faster charge/discharge, which consequently accelerates the ions removal from the solution.

\section{Conclusions.}

In summary, activation of GO using a novel electrochemical method at low temperature has been used to engineer 3D porous nanoarchitecture electrode for supercapacitor and capacitive deionization devices. The activation process is based on switching the polarity between 2 symmetrical GO electrodes in molten $\mathrm{KOH}$, which also efficiently removed the oxygen functional groups. The resulted electrodes exhibited high specific surface area $\left(2170 \mathrm{~m}^{-1} \mathrm{~g}^{-1}\right.$, as well as mesopores and micropores structures, which significantly enhanced the electrochemical performance. In particular, the supercapacitor device showed specific capacitance as high as $275 \mathrm{~F} \mathrm{~g}^{-1}$ in $\mathrm{KOH}$ solution and maintained $95 \%$ of this value after 5000 cycles. The ECAG electrode showed high adsorption capacity in CDI system with enhanced kinetic and energy efficiency, making it a strong candidate for water desalination application.

\section{Supporting Information}

The Supporting Information is available free of charge on the ACS Publications website

XPS survey spectra of the GO and the ECAG, TGA, More analysis for the electrochemical performance of the ECAG electrode, graphic of the electrochemical reactor, comparison of the ECAG electrode with other materials in the literature.

\section{Acknowledgment}

The Deanship of Scientific Research (DSR), at King Abdulaziz University, Jeddah, funded this project under grant no. (G-422-829-37). The authors, therefore, acknowledge with thanks, DSR technical and financial support. The authors would also like to thank Tyler Lieberthal for helping with the graphics. 


\section{References:}

1. Suss, M. E.; Porada, S.; Sun, X.; Biesheuvel, P. M.; Yoon, J.; Presser, V., Water desalination via capacitive deionization: what is it and what can we expect from it? Energ. Environ. Sci. 2015, 8, 2296-2319.

2. Anderson, M. A.; Cudero, A. L.; Palma, J., Capacitive deionization as an electrochemical means of saving energy and delivering clean water. Comparison to present desalination practices: Will it compete? Electrochim. Acta 2010, 55, 38453856.

3. Porada, S.; Zhao, R.; van der Wal, A.; Presser, V.; Biesheuvel, P. M., Review on the science and technology of water desalination by capacitive deionization. Prog. Mater Sci. 2013, 58, 1388-1442.

4. Oren, Y., Capacitive deionization (CDI) for desalination and water treatment past, present and future (a review). Desalination 2008, 228, 10-29.

5. Humplik, T.; Lee, J.; O'Hern, S. C.; Fellman, B. A.; Baig, M. A.; Hassan, S. F.; Atieh, M. A.; Rahman, F.; Laoui, T.; Karnik, R.; Wang, E. N., Nanostructured materials for water desalination. Nanotechnology 2011, 22, 292001.

6. Pekala, R. W.; Farmer, J. C.; Alviso, C. T.; Tran, T. D.; Mayer, S. T.; Miller, J. M.; Dunn, B., Carbon aerogels for electrochemical applications. J. Non-Cryst. Solids 1998, 225, 74-80.

7. Futaba, D. N.; Hata, K.; Yamada, T.; Hiraoka, T.; Hayamizu, Y.; Kakudate, Y.; Tanaike, O.; Hatori, H.; Yumura, M.; lijima, S., Shape-engineerable and highly densely packed single-walled carbon nanotubes and their application as super-capacitor electrodes. Nat Mater 2006, 5, 987-994.

8. Mauter, M. S.; Elimelech, M., Environmental applications of carbon-based nanomaterials. Environ. Sci. Technol. 2008, 42, 5843-5859.

9. Sui, Z.; Meng, Q.; Zhang, X.; Ma, R.; Cao, B., Green synthesis of carbon nanotube-graphene hybrid aerogels and their use as versatile agents for water purification. J. Mater. Chem. 2012, 22, 8767-8771.

10. Li, H.; Zou, L.; Pan, L.; Sun, Z., Novel graphene-like electrodes for capacitive deionization. Environ. Sci. Technol. 2010, 44, 8692-8697.

11. Yang, X.; Zhu, J.; Qiu, L.; Li, D., Bioinspired Effective Prevention of Restacking in Multilayered Graphene Films: Towards the Next Generation of High-Performance Supercapacitors. Adv. Mater. 2011, 23, 2833-2838.

12. Zhu, Y.; Murali, S.; Stoller, M. D.; Ganesh, K. J.; Cai, W.; Ferreira, P. J.; Pirkle, A.; Wallace, R. M.; Cychosz, K. A.; Thommes, M.; Su, D.; Stach, E. A.; Ruoff, R. S., Carbon-Based Supercapacitors Produced by Activation of Graphene. Science 2011, 332, 1537-1541.

13. Abdelkader, A. M., Electrochemical synthesis of highly corrugated graphene sheets for high performance supercapacitors. J. Mater. Chem. A 2015, 3, 8519-8525. 14. Mendoza-Sánchez, B.; Gogotsi, Y., Synthesis of Two-Dimensional Materials for Capacitive Energy Storage. Adv. Mater. 2016, 6104-6135.

15. Hu, C.; Song, L.; Zhang, Z.; Chen, N.; Feng, Z.; Qu, L., Tailored graphene systems for unconventional applications in energy conversion and storage devices. Energ. Environ. Sci. 2015, 8, 31-54.

16. Yu, G.; Xie, X.; Pan, L.; Bao, Z.; Cui, Y., Hybrid nanostructured materials for high-performance electrochemical capacitors. Nano Energy 2013, 2, 213-234. 
17. Yan, Z.; Yao, W.; Hu, L.; Liu, D.; Wang, C.; Lee, C. S., Progress in the preparation and application of three-dimensional graphene-based porous nanocomposites. Nanoscale 2015, 7, 5563-5577.

18. Lim, E.; Jo, C.; Kim, M. S.; Kim, M. H.; Chun, J.; Kim, H.; Park, J.; Roh, K. C.; Kang, K.; Yoon, S.; Lee, J., High-Performance Sodium-Ion Hybrid Supercapacitor Based on $\mathrm{Nb2O} 5$ at Carbon Core-Shell Nanoparticles and Reduced Graphene Oxide Nanocomposites. Adv. Funct. Mater. 2016, 3711-3719.

19. Yan, J.; Liu, J.; Fan, Z.; Wei, T.; Zhang, L., High-performance supercapacitor electrodes based on highly corrugated graphene sheets. Carbon 2012, 50, 21792188.

20. Xia, X. H.; Chao, D. L.; Zhang, Y. Q.; Shen, Z. X.; Fan, H. J., Three-dimensional graphene and their integrated electrodes. Nano Today 2014, 9, 785-807.

21. Cao, X.; Yin, Z.; Zhang, H., Three-dimensional graphene materials: Preparation, structures and application in supercapacitors. Energ. Environ. Sci. 2014, 7, 1850-1865.

22. Abdelkader, A. M.; Vallés, C.; Cooper, A. J.; Kinloch, I. A.; Dryfe, R. A. W., Alkali reduction of graphene oxide in molten halide salts: Production of corrugated graphene derivatives for high-performance supercapacitors. ACS Nano 2014, 8 , 11225-11233.

23. Lei, H.; Yan, T.; Wang, H.; Shi, L.; Zhang, J.; Zhang, D., Graphene-like carbon nanosheets prepared by a Fe-catalyzed glucose-blowing method for capacitive deionization. J. Mater. Chem. A 2015, 3, 5934-5941.

24. Frackowiak, E.; Delpeux, S.; Jurewicz, K.; Szostak, K.; Cazorla-Amoros, D.; Béguin, F., Enhanced capacitance of carbon nanotubes through chemical activation. Chem. Phys. Lett. 2002, 361, 35-41.

25. Stoller, M. D.; Park, S.; Yanwu, Z.; An, J.; Ruoff, R. S., Graphene-Based ultracapacitors. Nano Lett. 2008, 8, 3498-3502.

26. Ma, Y.; Chang, H.; Zhang, M.; Chen, Y., Graphene-based materials for lithiumion hybrid supercapacitors. Adv. Mater. 2015, 27, 5296-5308.

27. Xu, J.; Tan, Z.; Zeng, W.; Chen, G.; Wu, S.; Zhao, Y.; Ni, K.; Tao, Z.; Ikram, M.; Ji, H.; Zhu, Y., A Hierarchical Carbon Derived from Sponge-Templated Activation of Graphene Oxide for High-Performance Supercapacitor Electrodes. Adv. Mater. 2016, 28, 5222-5228.

28. Hummers Jr, W. S.; Offeman, R. E., Preparation of graphitic oxide. J. Am. Chem. Soc. 1958, 80, 1339-1339.

29. Park, S.; An, J.; Piner, R. D.; Jung, I.; Yang, D.; Velamakanni, A.; Nguyen, S. T.; Ruoff, R. S., Aqueous suspension and characterization of chemically modified graphene sheets. Chem. Mater. 2008, 20, 6592-6594.

30. Abdelkader, A. M.; Fray, D. J., Direct electrochemical preparation of Nb-10Hf1Ti alloy. Electrochimica Acta 2010, 55, 2924-2931.

31. Abdelkader, A. M.; Hyslop, D. J. S.; Cox, A.; Fray, D. J., Electrochemical synthesis and characterization of a $\mathrm{NdCo} 5$ permanent magnet. J. Mater. Chem. 2010, 20, 6039-6049.

32. Sing, K. S. W.; Everett, D. H.; Haul, R. A. W.; Moscou, L.; Pierotti, R. A.; Rouquerol, J.; Siemieniewska, T., Reporting Physisorption Data for Gas/Solid Systems with Special Reference to the Determination of Surface Area and Porosity. Pure Appl. Chem. 1985, 57, 603-619. 
33. Wang, J.; Kaskel, S., $\mathrm{KOH}$ activation of carbon-based materials for energy storage. J. Mater. Chem. 2012, 22, 23710-23725.

34. Wu, S.; Chen, G.; Kim, N. Y.; Ni, K.; Zeng, W.; Zhao, Y.; Tao, Z.; Ji, H.; Lee, Z.; Zhu, Y., Creating Pores on Graphene Platelets by Low-Temperature KOH Activation for Enhanced Electrochemical Performance. Small 2016, 12, 2376-2384.

35. Chen, W.; Yan, L.; Bangal, P. R., Preparation of graphene by the rapid and mild thermal reduction of graphene oxide induced by microwaves. Carbon 2010, 48, 1146-1152.

36. Abdelkader, A. M.; Kinloch, I. A.; Dryfe, R. A. W., High-yield electro-oxidative preparation of graphene oxide. Chem. Commun. 2014, 50, 8402-8404.

37. Abdelkader, A. M.; Kinloch, I. A., Mechanochemical Exfoliation of 2D Crystals in Deep Eutectic Solvents. ACS Sustainable Chemistry and Engineering 2016, 4, 44654472.

38. Abdelkader, A. M.; Patten, H. V.; Li, Z.; Chen, Y.; Kinloch, I. A., Electrochemical exfoliation of graphite in quaternary ammonium-based deep eutectic solvents: a route for the mass production of graphane. Nanoscale 2015, 7, 11386-11392.

39. Li, H.; Pan, L.; Nie, C.; Liu, Y.; Sun, Z., Reduced graphene oxide and activated carbon composites for capacitive deionization. J. Mater. Chem. 2012, 22, 1555615561.

40. Liu, P.; Wang, H.; Yan, T.; Zhang, J.; Shi, L.; Zhang, D., Grafting sulfonic and amine functional groups on 3D graphene for improved capacitive deionization. $J$. Mater. Chem. A 2016, 4, 5303-5313.

41. Wen, X.; Zhang, D.; Yan, T.; Zhang, J.; Shi, L., Three-dimensional graphenebased hierarchically porous carbon composites prepared by a dual-template strategy for capacitive deionization. J. Mater. Chem. A 2013, 1, 12334-12344.

42. Wang, H.; Zhang, D.; Yan, T.; Wen, X.; Zhang, J.; Shi, L.; Zhong, Q., Threedimensional macroporous graphene architectures as high performance electrodes for capacitive deionization. J. Mater. Chem. A 2013, 1, 11778-11789.

43. Wang, H.; Shi, L.; Yan, T.; Zhang, J.; Zhong, Q.; Zhang, D., Design of graphenecoated hollow mesoporous carbon spheres as high performance electrodes for capacitive deionization. J. Mater. Chem. A 2014, 2, 4739-4750.

44. Rasines, G.; Lavela, P.; Macías, C.; Zafra, M. C.; Tirado, J. L.; Parra, J. B.; Ania, C. O., N-doped monolithic carbon aerogel electrodes with optimized features for the electrosorption of ions. Carbon 2015, 83, 262-274.

45. Zhao, R.; Biesheuvel, P. M.; Miedema, H.; Bruning, H.; van der Wal, A., Charge Efficiency: A Functional Tool to Probe the Double-Layer Structure Inside of Porous Electrodes and Application in the Modeling of Capacitive Deionization. J. Phy. Chem. Lett. 2010, 1, 205-210.

46. Porada, S.; Weinstein, L.; Dash, R.; van der Wal, A.; Bryjak, M.; Gogotsi, Y.; Biesheuvel, P. M., Water Desalination Using Capacitive Deionization with Microporous Carbon Electrodes. ACS Applied Materials \& Interfaces 2012, 4, 11941199.

47. Avraham, E.; Noked, M.; Cohen, I.; Soffer, A.; Aurbach, D., The Dependence of the Desalination Performance in Capacitive Deionization Processes on the Electrodes PZC. J. Electrochem. Soc. 2011, 158, P168-P173.

48. Cohen, I.; Avraham, E.; Noked, M.; Soffer, A.; Aurbach, D., Enhanced Charge Efficiency in Capacitive Deionization Achieved by Surface-Treated Electrodes and by 
Means of a Third Electrode. The Journal of Physical Chemistry C 2011, 115, 1985619863.

49. Gao, X.; Omosebi, A.; Landon, J.; Liu, K., Enhanced Salt Removal in an Inverted Capacitive Deionization Cell Using Amine Modified Microporous Carbon Cathodes. Environ. Sci. Technol. 2015, 49, 10920-10926. 


\section{For Table of Contents Use Only}

Electrochemical activation of graphene at low temperature: the synthesis of three-dimensional nanoarchitectures for high performance supercapacitor and capacitive deionization

M. Sh. Zoromba, M. H. Abdel-Aziz, M. Bassyouni, Saud Abdulaziz, Gutub, Denisa Demko, Amr M. Abdelkader

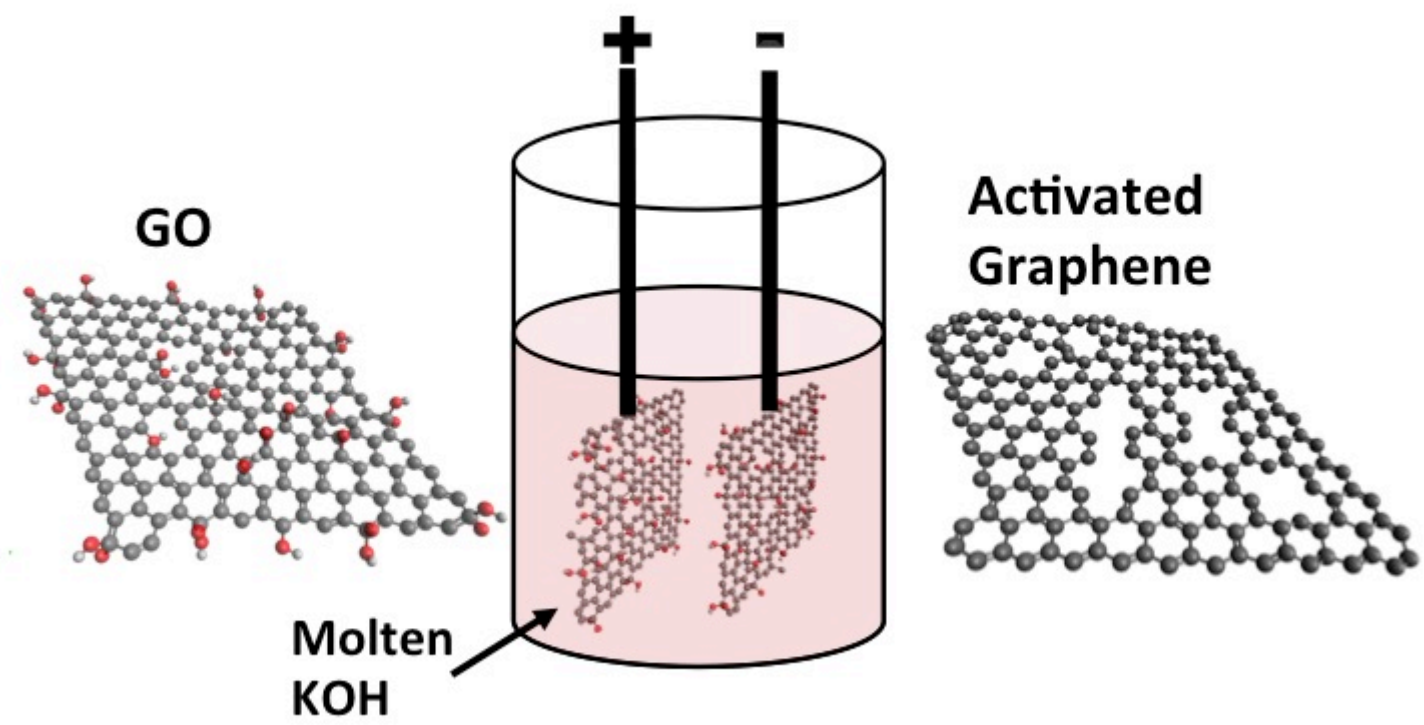

Porous graphene based electrodes for energy storage and water desalination was fabricated using novel electrochemical activation process at low temperature 